Louisiana State University

LSU Digital Commons

$5-1-2011$

\title{
Metabolic restructuring during energy-limited states: Insights from Artemia franciscana embryos and other animals
}

\author{
Steven C. Hand \\ Louisiana State University \\ Michael A. Menze \\ Eastern Illinois University \\ Apu Borcar \\ Louisiana State University \\ Yuvraj Patil \\ Louisiana State University \\ Joseph A. Covi \\ University of Wisconsin-Stevens Point
}

See next page for additional authors

Follow this and additional works at: https://digitalcommons.Isu.edu/biosci_pubs

\section{Recommended Citation}

Hand, S., Menze, M., Borcar, A., Patil, Y., Covi, J., Reynolds, J., \& Toner, M. (2011). Metabolic restructuring during energy-limited states: Insights from Artemia franciscana embryos and other animals. Journal of Insect Physiology, 57 (5), 584-594. https://doi.org/10.1016/j.jinsphys.2011.02.010 


\section{Authors}

Steven C. Hand, Michael A. Menze, Apu Borcar, Yuvraj Patil, Joseph A. Covi, Julie A. Reynolds, and Mehmet Toner 


\title{
Metabolic Restructuring during Energy-Limited States: Insights from Artemia franciscana Embryos and Other Animals
}

\author{
Steven C. Hand ${ }^{a, 1}$, Michael A. Menze ${ }^{b}$, Apu Borcara, Yuvraj Patila, Joseph A. Coviic, Julie A. \\ Reynolds ${ }^{d}$, and Mehmet Toner ${ }^{\mathrm{e}}$ \\ aDivision of Cellular, Developmental and Integrative Biology, Department of Biological Sciences, \\ Louisiana State University, Baton Rouge, LA 70803 USA \\ ${ }^{b}$ Department of Biological Sciences, Eastern Illinois University, Charleston, IL 61920 USA \\ 'Department of Biology, University of Wisconsin-Stevens Point, Stevens Point, WI 54481 USA \\ dDepartment of Entomology, Ohio State University, Columbus OH 43210 USA \\ 'Center for Engineering in Medicine and Surgical Services, Massachusetts General Hospital, \\ Harvard Medical School and Shriners Hospitals for Children, Boston, MA 02114 USA
}

\begin{abstract}
Many life history stages of animals that experience environmental insults enter developmental arrested states that are characterized by reduced cellular proliferation, with or without a concurrent reduction in overall metabolism. In the case of the most profound metabolic arrest reported in invertebrates, i.e., anaerobic quiescence in Artemia franciscana embryos, acidification of the intracellular milieu is a major factor governing catabolic and anabolic downregulation. Release of ion gradients from intracellular compartments is the source for approximately $50 \%$ of the proton equivalents needed for the 1.5 unit acidification that is observed. Recovery from the metabolic arrest requires re-sequestration of the protons with a vacuolar-type ATPase (V-ATPase). The remarkable facet of this mechanism is the ability of embryonic cells to survive the dissipation of intracellular ion gradients. Across many diapause-like states, the metabolic reduction and subsequent matching of energy demand is accomplished by shifting energy metabolism from oxidative phosphorylation to aerobic glycolysis. Molecular pathways that are activated to induce these resilient hypometabolic states include stimulation of the AMP-activated protein kinase (AMPK) and insulin signaling via suite of $d a f$ (dauer formation) genes for diapause-like states in nematodes and insects. Contributing factors for other metabolically-depressed states involve hypoxia-inducible factor-1 and downregulation of the pyruvate dehydrogenase complex. Metabolic similarities between natural states of stasis and some cancer phenotypes are noteworthy. Reduction of flux through oxidative phosphorylation helps prevent cell death in certain cancer types, similar to the way it increases viability of dauer stages in Caenorhabditis elegans. Mechanisms that underlie natural stasis are being used to precondition mammalian cells prior to cell biostabilization and storage.
\end{abstract}

\footnotetext{
(C) 2011 Elsevier Ltd. All rights reserved.

${ }^{1}$ To whom correspondence should be addressed. shand@LSU.edu. .
}

Publisher's Disclaimer: This is a PDF file of an unedited manuscript that has been accepted for publication. As a service to our customers we are providing this early version of the manuscript. The manuscript will undergo copyediting, typesetting, and review of the resulting proof before it is published in its final citable form. Please note that during the production process errors may be discovered which could affect the content, and all legal disclaimers that apply to the journal pertain. 


\section{Keywords}

metabolic depression; diapause; anoxia; vacuolar-ATPase; intracellular pH; metabolic preconditioning; glycolysis; oxidative phosphorylation; hypoxia inducible factor-1

\section{Introduction}

The ability to arrest development and metabolism prior to environmental challenges like desiccation, anoxia, and freezing improves the survival of many species (Buck and Hochachka, 1993; Crowe and Clegg, 1978; Clegg, 2005; Guppy et al., 1994; Guppy and Wither, 1999; Hand, 1991; Hand and Hardewig, 1996; Hand and Menze, 2008; Hochachka and Guppy, 1987; Lutz, 1992; Podrabsky et al, 2007; Storey, 2007; Storey and Storey, 2007). For example, invertebrate diapause is a state of developmental and/or metabolic arrest controlled by endogenous cellular factors, such that entry into diapause in nature precedes the onset of stressful environmental conditions (Alekseev et al., 2007; Cáceres, 1997; Denlinger, 2002; Lees, 1955; Hahn and Denlinger, 2007, 2011; Tauber and Tauber, 1976). What occurs during entry into diapause is that animals interrupt their normal developmental program. Complex metabolic processes are carefully downregulated in a coordinated fashion, which minimizes imbalances in cellular processes that can cause pathological conditions to develop. Diapausing organisms remain hypometabolic even under conditions that would normally promote active metabolism and development. In this regulated state of stasis, diapausing animal are more tolerant of environmental stresses. Further, the greater the arrest of metabolism during energy limited states like anoxia, the longer is the survivorship in the dormant state (Hand, 1998).

The requirements for an organism to survive a hypometabolic state include (but are not limited to) the suppression of oxidative pathways of energy production, the suppression of energy consumption (e.g., transcription, translation, ion pumping), extension of macromolecular half-lives, and avoidance of unwarranted apoptosis (Buck and Hochachka, 1993; Clegg, 2007; Guppy et al., 1994; Hand and Menze, 2008; Hand and Hardewig, 1996; Hochachka and Guppy, 1987; Lutz, 1992; Menze et al. 2010b; Storey and Storey, 2007). The suppression of oxidative pathways in particular is a key to recovering from hypometabolic states; otherwise, cellular energy reserves become depleted and organisms reach energetic states from which recovery is not possible. Downregulation of specific gene products, and in some instances upregulation, may be useful in promoting the diapause state (e.g., Menze et al., 2009; Ragland et al., 2010; Reynolds and Hand, 2009b; Rinehart et al., 2010; Urbanski et al., 2010; van Breukelen et al., 2000). Preservation of existing macromolecules is accomplished by directly reducing degradation rates (Anchordoguy and Hand, 1995; van Breukelen and Hand, 2000; Warner et al., 1997) and through the actions of protective intracellular solutes (Hoekstra et al., 1997; Crowe et al., 1997) and molecular chaperones (Clegg, 2001, 2007).

The goals of this review are to evaluate features of the metabolic restructuring inherent in energy-limited states like diapause and anoxia-induced quiescence, and to review some of the proximal mechanisms promoting the downregulation. Finally, we will consider various applications of these concepts - derived from natural biological states - to enhance the success of biostabilization of mammalian cells. One key prediction is that forcing mammalian cells into stasis (defined here as cellular and developmental arrest under hydrated conditions at euthermic temperatures) will foster greater survivorship of cells when exposed to stabilization methods like dehydration, lyophilization and cryopreservation. 


\section{Developmental and metabolic arrest do not always coincide}

Commonly, when development is suspended as a result of entry into diapause or environmentally induced quiescence, there is a concomitant and acute depression of metabolism. One example, which to our knowledge is the most profound metabolic depression ever reported during a diapause state, is seen in embryos of the brine shrimp, Artemia franciscana (Clegg et al., 1996; Reynolds and Hand, 2004). This anostracan crustacean inhabits hypersaline bodies of water such as the Great Salt Lake, Utah. Females release diapause embryos that display a $90 \%$ drop in respiration rate, as measured for fieldcollected embryos (Fig. 1). The measured depression is even greater (97\%) when embryos are synchronized for time of diapause entry (Clegg et al., 1996). This metabolic arrest that accompanies diapause occurs under fully normoxic and hydrated conditions. Similarly, oxygen consumption is reduced by $87 \%$ in embryos of the field cricket, Gryllus pennsylvanicus (Rakshpal, 1962).

In contrast, there are a number of diapause cases for which it is clear that developmental arrest is uncoupled from metabolic arrest. In embryos of the Southern ground cricket, Allonemobius socius, acute depression of aerobic metabolism does not accompany the entry into diapause (Reynolds and Hand, 2009a). Diapause entry is defined as the point at which development ceases (4-5 days post-oviposition), as measured by blockage of morphological change and cell proliferation. DNA content is an indirect measure of cell proliferation (cell number), and oxygen consumption per embryo increases linearly with increasing DNA content. The abrupt arrest of cell proliferation shows that diapause serves the purpose of postponing progression through the life cycle as part of an overwintering strategy, but energy metabolism does not drop below that measured at the point of diapause entry (Reynolds and Hand, 2009a; Fig. 2). This observation is rather unexpected, because shutting down the biosynthesis of expensive macromolecules needed for proliferation (e.g., DNA and protein) should reduce metabolic expenditure. The possibility that glycolysis-derived energy might support a large fraction of the proliferation (and thus its depression overlooked during diapause entry due to quantification solely by oxygen consumption) was ruled out by simultaneous measurements with microcalorimetry. Calorimetric-respirometric ratios did not reveal any anaerobic contribution to energy metabolism in non-diapause, proliferating embryos (Reynolds and Hand, 2009a). In some forms of insect diapause (i.e., at the pupal stage), metabolic rate can be cyclical during diapause (Denlinger et al., 1972; Slama and Denlinger, 1992). We have no evidence for pulsatile respiration in A. socius embryos; our measurements were averaged over relatively short time intervals of $1 \mathrm{~h}$.

The respiration rate of non-diapausing embryos continues to increase several fold as development progresses, and this ontogenetic increase is blocked during diapause, such that metabolic rate of diapause embryos is only $36 \%$ of the rate measured for developing embryos at 15 days (Reynolds and Hand, 2009a). The lack of significant metabolic arrest during diapause is not unique to A. socius because embryos of the grasshopper Alocara elliot continue to consume oxygen at a 'pre-diapause' rate even after entering diapause (Roemhild, 1965). Many species of insects remain responsive to changes in environmental conditions throughout diapause (Kostál, 2006), and consequently it is probable that if metabolic downregulation in A. socius were to occur in nature it would be mediated by external factors (e.g. low temperature, hypoxia) rather than internal mechanisms. Nevertheless, the biological explanation and importance for such decoupling of metabolism and development during diapause entry is currently unexplained.

Both non-diapause and diapause embryos have unusually high [AMP]:[ATP] ratios and low [ATP]:[ADP] ratios during early embryogenesis (Fig 3.), which suggests embryos may have experienced hypoxia as a result of the serosal cuticle or other extraembryonic membrane that 
limits water loss but may restrict oxygen diffusion. An attractive hypothesis is that activation of the AMP-activated protein kinase (AMPK) is responsible in some way for diapause entry in A. socius. AMPK is a fuel-sensing enzyme that is activated by decreases in a cell's energy state as reflected by an increased AMP:ATP ratio. AMPK serves as a metabolic fuel gauge and is part of a signaling cascade that modulates a number of metabolic processes including, but not limited to, inhibition of cell proliferation (Hardie, 2007; Ruderman et al., 2010; Steinberg and Kemp, 2009). AMPK activity is required to inhibit cell proliferation during dauer formation in Caenorhabditis elegans (Narbonne and Roy, 2006). In diapause states for the annual killifish Austrofundulus limnaeus (see Section 4.2) and A. franciscana embryos (Reynolds, Covi, Menze and Hand, unpublished), an increase in the AMP:ATP ratio occurs that may activate this enzyme. However, for $A$. socius, because AMP:ATP ratios are equivalent between diapause and non-diapause embryos and the highest AMP:ATP ratios are present before onset of developmental arrest, it is improbable that AMPK is directly responsible for diapause entry. Thus, while unlikely to be universal mechanism for regulating diapause induction, [AMP]:[ATP] ratios may activate AMPK and contribute to metabolic downregulation in some diapausing species.

It is noteworthy that a similar decoupling of metabolism and development has been reported during diapause in embryos of the annual killifish Austrofundulus limnaeus (Podrabsky and Hand, 1999). Surprisingly in this case, a major decline in metabolism (as judged by heart rate, heat dissipation rate and oxygen consumption) precedes the developmental arrest by several days. Yet during this developmental period when depression of metabolism is evident, there are significant increases in total DNA content and embryonic complexity. If the metabolic decline is strictly associated with diapause (an alternative exists, cf. Podrabsky and Hand, 1999), the early metabolic depression may reflect a sequential exit of dividing cells from the cell cycle in an anterior-to-posterior fashion. Thus, while major developmental processes may be complete in the anterior region, the posterior region may still be developing. Such a pattern could explain how muscle somites are still being added in the posterior region, yet metabolic rate is already declining after 8 days post-fertilization as a result of cell cycle arrest in the more anterior regions. From the above examples, it is abundantly clear that one should not assume a depression in energy metabolism simply because a developmental arrest occurs during diapause entry.

\section{Arrest and restructuring of metabolic during cell stasis}

\subsection{Modulation by intracellular $\mathrm{pH}$ and mechanism for the acidification}

Embryos of A. franciscana tolerate anoxia for periods of years in the fully hydrated state and at euthermic temperatures (Warner and Clegg, 2001; Clegg, 1997). During anoxia-induced quiescence, metabolism is reduced to virtually immeasurable levels (Hand, 1995; Clegg, 1997); metabolic depression is accompanied by acute developmental arrest (e.g., Dutrieu and Chrestia-Blanchine, 1966). The impact of intracellular acidification on the metabolic transition into anaerobic quiescence in embryos of A. franciscana is well documented and multiple reviews are available (Busa and Nuccitelli, 1984; Busa, 1985; Hand, 1997, 1998; Hand and Hardewig, 1996). Thus we will not review the topic here, but will simply point out that the largest transition in intracellular $\mathrm{pH}\left(\mathrm{pH}_{\mathrm{i}}\right)$ ever reported for eukaryotic cells $\left(\mathrm{pH}_{\mathrm{i}}\right.$ $\geq 7.9$ to 6.3 ) occurs during the transition from aerobic development to anaerobic quiescence in A. franciscana embryos, and this proton accumulation has profound inhibitory impacts on energy metabolism, gene expression, biosynthesis and macromolecular turnover (Hand et al 2001; Hand and Podrabsky, 2000; Clegg, 2007; Hand and Menze, 2008). For an assessment of whether or not there is a role for $\mathrm{pH}_{\mathrm{i}}$ in promoting diapause entry in A. franciscana embryos, see Clegg (2011, this issue). 
The issue that eluded explanation for 23 years is the source of protons for the impressive acidification under anoxia described above (Busa et al., 1982; Covi and Hand, 2005b). Previous work shows a massive drop in the cellular ATP:ADP ratio occurs under anoxia in these embryos (Anchordoguy and Hand, 1994; Stocco et al., 1972) that produces a net release of protons. When combined with hydrolysis of other NTPs and small amounts of organic acid production, calculations indicate the drop in ATP could account for a maximum of perhaps $72 \%$ of the proton equivalents required for the observed acidification (Kwast et al., 1995). However more conservative calculations suggest the explained acidification could be as low 20-26\% (Busa and Nuccitelli, 1984; Kwast et al., 1995). Clearly, insufficient proton equivalents are identified thus far to explain the transients in $\mathrm{pH}_{\mathrm{i}}$ observed during entry and exit from anoxia. A novel mechanism to resolve this problem is developed and tested by Covi and Hand (2005) and Covi et al. (2005), and then combined with a study that measures the metabolic costs of the process (Covi and Hand, 2007).

The concept proposes that during aerobic development of the embryos a vacuolar proton pump (V-ATPase; the expression of which is documented; Covi and Hand, 2005) first compartmentalizes the protons into membrane-bound intracellular compartments, not unlike the acidic compartments observed in many eukaryotic cells. These compartments presumably would include Golgi complex, exocytotic and endosomal vesicles, lysosomes, and yolk platelets. Then exposure of embryos to anoxia releases protons from the acidic compartments to the surrounding cytoplasm. Calculations indicate this mechanism could account for $50 \%$ of the required protons needed to explain the $1 \mathrm{pH}$ unit shift during the early phase of anoxia exposure (Covi and Hand, 2005). It is appropriate to note that $\mathrm{pH}_{\mathrm{i}}$ values for these embryos are obtained with ${ }^{31} \mathrm{P}-\mathrm{NMR}$. Thus, protons stored in these intracellular membrane-bound compartments, which are presumed to have low phosphate concentrations, would remain undetected by ${ }^{31} \mathrm{P}-\mathrm{NMR}$ until their release into the cytoplasmic compartment with its relatively high $\mathrm{P}_{\mathrm{i}}$ content.

Evidence for this mechanism is generated by ${ }^{31} \mathrm{P}-\mathrm{NMR}$ measurements of embryos during the aerobic recovery from anoxia. Covi et al. (2005) demonstrate that in vivo inhibition of VATPase activity by bafilomycin blocks recovery from the intracellular acidification induced by anoxia. With bafilomycin, the embryo $\mathrm{pH}_{\mathrm{i}}$ recovers only from $\mathrm{pH} 6.6$ to 6.9 (Fig. 4), in contrast to the full recovery of $\mathrm{pH}_{\mathrm{i}}$ to 7.9 seen without bafilomycin. Oxidative phosphorylation and ATP resynthesis only accounts for the first $0.3 \mathrm{pH}$ unit alkalinization observed during aerobic recovery from the $1 \mathrm{pH}$ unit acidification produced during $1 \mathrm{~h}$ of anoxia. The additional $0.7 \mathrm{pH}$ unit increase requires proton pumping by the V-ATPase. Thus, sequestration of protons in compartment(s) with low $\mathrm{P}_{\mathrm{i}}$ content is the major contributor to intracellular alkalinization during aerobic recovery from anoxia.

Covi et al. (2005) also show that global dissipation of proton gradients with carbonyl cyanide 3-chlorophenylhydrazone (CCCP) in the presence of oxygen yields an acidic $\mathrm{pH}_{\mathrm{i}}$ similar to that observed after $1 \mathrm{~h}$ of anoxia; further, anoxia exposure of the CCCP-treated embryos does not acidify the $\mathrm{pH}_{\mathrm{i}}$ any further. These combined data strongly support the hypothesis that dissipation of proton gradients are a key contributor to anoxia-induced acidification of the intracellular space in A. franciscana embryos. Indeed, when combined with the protons produced by net hydrolysis of NTPs (Busa and Nuccitelli, 1984; Kwast et al., 1995), the collapse of proton chemical gradients can fully explain the origin of acid equivalents required for this acidification (see model presented in Fig. 5).

Finally, given the complete absence of detectable $\mathrm{Na}^{+} \mathrm{K}^{+}$-ATPase activity during the preemergence development of A. franciscana embryos, Covi and Hand (2007) postulate that the V-ATPase may perform a role in both the acidification of intracellular compartments and the energization of plasma membranes. The V-ATPase inhibitor bafilomycin produces a 
concentration-dependent inhibition of oxygen consumption in aerobic embryos. Respirometric data indicates that proton pumping by the V-ATPase, and processes immediately dependent on this activity, constitutes approximately $31 \%$ of the aerobic energy budget of the preemergent embryo (Fig. 6). The high metabolic cost associated with maintaining these diverse proton gradients requires that V-ATPase activity be downregulated under anoxia in order to attain the almost complete metabolic depression observed in the quiescent embryo. Downregulation of the V-ATPase pump is most likely accomplished within minutes by the rapid drop in the ATP:ADP ratio and increased free $P_{i}$ during entry into anoxia (Covi and Hand, 2005). Reversible dissociation appears to be the primary mechanism by which V-ATPase activity is regulated (Wieczorek et al 2003), although recent data suggests that changes in phospholipid content may also play a regulatory role (Zhang et al. 2010, Lafourcade et al. 2008). Given the acute time frame of the response to anoxic transitions in A. franciscana, it is relevant to note that reversible dissociation may occur in response to energy limitation (Kane and Smardon, 2003), and reassembly and activation of the V-ATPase is mediated by PKA (Alzamora et al. 2010; Rein et al. 2007).

\section{Comparison of metabolic remodeling in other selected animals}

\subsection{Dauer larvae of Caenorhabditis elegans}

C. elegans 'dauer' larvae are induced to enter a state of developmental and metabolic arrest by environmental and physiological cues such as starvation, hypoxia, over-crowding, desiccation and unfavorable temperatures (Cassada and Russel, 1975; Fielenbach and Antebi, 2008; Mabon et al., 2009; Riddle and Albert, 1997). C. elegans develop from egg to adult phase in about 3 days, and adults have an average life span of 13 days (Gems et al., 1999; Holt and Riddle, 2003). However, dauer larvae can survive for several months without feeding, and the time spend in the dauer state has no effect on the adult life span. Dauer larvae exhibit a low rate of oxygen consumption rate consistent with reduced metabolic rates (Vanfleteren and De Vreese, 1996; Houthoofd et al., 2002). O'Riordan and Burnell (1989) found that activities for enzymes involved in the Krebs cycle were lower in dauer larvae than in adults. The flux of metabolites through the Kreb's cycle was found to be 11-fold lower in dauer larvae than in adults. However, dauer larvae have an active glyoxylate cycle (Vanfleteren and De Vreese, 1995) and fatty-acid oxidation enzymes, which indicates their capacity for conversion of fatty acids to carbohydrate (O'Riordan and Burnell, 1990).

Wang and Kim (2003) show upregulation of genes encoding pyruvate kinase and phosphofructokinse (PFK) during the dauer stage, and O'Riordan and Burnell (1989) report upregulation of PFK activity. These observations suggest glycolytic capacity is elevated during the dauer stage. Because genes for glycogen utilization do not appear to be upregulated during the dauer phase (Wang and Kim, 2003), a source of glucose other than glycogen may be available to the larvae. Trehalose levels are increased in the dauer stage as compared to the adult stage and may serve as the primary source of carbohydrate fuel (Fuchs et al., 2010).

Dauer larvae utilize alternative pathways of energy production involving fermentation. Entry into the dauer state is usually accompanied by formation of lactate, especially in hypoxic conditions (Holt and Riddle, 2003; Braeckman et al., 2009). Larvae in prolonged dauer phase show accumulation of ethanol as a predominant fermentation end product. The end products succinate and acetate are also generated in dauer larvae by mechanisms similar to those described for parasitic helminths (Tielens et al, 2002; Holt and Riddle, 2003). Upregulation of alcohol fermentation genes occur in dauer larvae (Holt and Riddle, 2003; Wang and Kim, 2003), and Glocker et al. (2008) show the upregulation of alcohol dehydrogenase protein levels. It is suggested that preferential alcohol fermentation in 
hypoxic tissue of dauer larval would provide metabolites to epidermal aerobic tissue that would enable it to conserve lipid reserves, which would in turn impart longevity (Holt and Riddle, 2003). The AMP-activated protein kinase (AMPK) analogue aak-2 prevents utilization of triglycerides in dauer larvae (Narbonne and Roy, 2009). aak-2 directly inactivates adipose triglyceride lipase (ATGL-1), which hydrolyzes the triglyceride pool to release fatty acids (Narbonne and Roy, 2009; Cunningham and Ashrafi, 2009).

Downregulation of ATGL-1 limits fat utilization and promotes viability and longevity in the dauer state. It should be immediately obvious that this role of AMPK for blocking fat utilization is diametrically opposed to the classical view from the mammalian literature that AMPK activation stimulates fat mobilization and oxidation (cf. Hardie, 2007). A crisper perspective on how the functions of AMPK change across diverse animal groups is needed. The regulation of lipid conservation during the dauer stage involves the insulin signaling pathway and utilizes a suite of $d a f$ (dauer formation) genes (Fielenbach and Antebi, 2008; Kenyon, 2010).

Such a pattern of lipid sparing is also supported during embryonic diapause in several insects (Kaocharern, 1958; Reynolds and Hand, 2009b; Visscher, 1976). For example, transcripts for enzymes that promote with fatty acid/lipid usage (ATP-citrate lyase, acylCoA reductase, lipid metabolism protein) are downregulated during diapause in cricket embryos (Reynolds and Hand, 2009b). Similar to its role in the regulation of dauer formation, insulin signaling is also known to be involved in insect diapause and to downregulate the fork-head transcription factor FOXO (Baker and Thummel, 2007; Hahn and Denlinger, 2011). Under conditions of low insulin, FOXO is active and controls a number of features related to the diapause phenotype, including lipid buildup (Hahn and Denlinger, 2011). Knockdown studies of FOXO show that lipid reserves characteristic of the overwintering diapause state of the mosquito Culex pipiens are not built up when this transcription factor is depressed (Sim and Denlinger, 2008).

\subsection{Austrofundulus limnaeus in diapause}

This annual killifish is briefly introduced earlier in the context of decoupling of metabolism and development during diapause (Section 2). Generally, annual killifish (Cyprinodontiformes, Rivulidae) occur in savanna and desert regions on the continents of Africa and South America. They inhabit ephemeral ponds in areas that experience pronounced dry and rainy seasons (Myers, 1952; Peters, 1963). Ponds inhabited by $A$. limnaeus dry out on a seasonal basis, killing the adult and juvenile forms (Nico and Thomerson, 1989). Populations persist in such situations as a result of the occurrence of diapause embryos embedded in the pond sediments. Podrabsky and Hand (1999) show that the rate of oxygen consumption and heat dissipation in early embryos of A. limnaeus peak at 8 days post-fertilization, followed by a continuous decline in these values until about 24 days post-fertilization. Oxygen consumption declines further over an additional 50 days to about $10 \%$ of the value determined at 8 days post-fertilization. Both indicators of metabolic rate therefore show a major depression of energy flow prior to entry into diapause as defined by the onset of developmental arrest (see Section 2). This metabolic depression is associated with a severe reduction in the rate of protein synthesis (Podrabsky and Hand, 2000).

Diapause embryos maintain high $[\mathrm{ATP}] /[\mathrm{ADP}]$ ratios and adenylate energy charge during diapause, consistent with a simultaneous depression of energy use and demand (Podrabsky and Hand, 1999). While the adenylate energy charge (AEC) is high during entry into diapause, there is a statistically significant decline during early diapause, which could be accounted by the increase in the AMP concentration across this period. There is an increase in the $[\mathrm{AMP}] /[\mathrm{ATP}]$ ratio observed after 8 days post-fertilization that is negatively correlation with the rates of oxygen consumption and heat dissipation. Elevated levels of AMP are therefore suggested to contribute to the depression of metabolism during early 
development and diapause in A. limnaeus (Podrabsky and Hand, 1999) via activation of AMPK (see Sections 2 and 5.2). Podrabsky and Hand (1999) estimate [AMP] in embryonic cells of A. limnaeus to be well over the activation threshold for the AMPK by 14 days postfertilization.

Embryos of A. limnaeus are likely to experience long bouts of severe hypoxia or anoxia in the environment in which they developmental (Podrabsky et al., 2007). Diapause embryos of A. limnaeus survive anoxia up to 30 days, while embryos in advanced stages of diapause survive even longer. A strong negative correlation between the rate of lactate production during anoxia and survival of anoxia reinforces the importance of metabolic rate depression to long-term survival of anoxia in embryos of A. limnaeus (Podrabsky et al., 2007). There appears to be an accumulation of free essential amino acids in embryos of A. limnaeus subjected to anoxia. Other amino acids such as glutamate, glutamine, aspartate and asparagines, which are elevated during normoxic development before entry into diapause, are depleted during the course of anoxic incubation. Podrabsky et al. (2007) suggest the role of these non-essential amino acids is to supply the citric acid cycle after transamination. They further propose that glutamate and glutamine are utilized in production of GABA, which is a potent inhibitory neurotransmitter that plays a role in protecting neural cells from excitotoxic cell death (Lutz and Milton, 2004; Cheung et al., 2006). Podrabsky et al. (2007) attribute the extreme anoxia tolerance of A. limnaeus embryos to key metabolic traits of diapause: depressed rates of metabolism, protein synthesis and ion transport and large stores of glycogen and amino acids like glutamate and glutamine.

\section{Application of metabolic preconditioning to biostabilization of mammalian cells}

As emphasized in Section 1, for animals whose evolutionary history has provided natural tolerance to anoxia, desiccation and freezing temperatures, metabolic depression is often a pre-requisite for survival. By considering this lesson from nature, one logical extrapolation is that preconditioning of mammalian cells to promote metabolic depression and proliferative stasis will foster greater survival of cells during biostabilization protocols that involve removal of cell water (lyopreservation) or cryopreservation (Hand and Hagedorn, 2008; Menze et al., 2010a).

\subsection{HIF-1 and pyruvate dehydrogenase during hypoxia and cancer}

One of the hallmark features of diapause in many species is the depression of oxidative phosphorylation under fully normoxic conditions. Similar metabolic restructuring is observed in some (but certainly not all) cancers that utilize the natural adaptive responses to hypoxia in order to survive and thrive (Bellance et al., 2009; Jezek, 2010; Heiden et al., 2009). If the cancerous metabolic phenotype (particularly as observed in various types of hard tumors) could be mimicked in non-cancerous cells, it is possible that tolerance of these cells to desiccation or subfreezing temperatures could be increased.

During hypoxia in mammalian cells one mechanism for depression of oxidative phosphorylation is the inactivation of the pyruvate dehydrogenase complex (PDC), which is responsible for the decarboxylation of pyruvate to acetyl-CoA in the mitochondrial matrix, after which the acetyl-CoA enters the citric acid cycle (Harris et al., 2002). PDC is strongly regulated by phosphorylation (inactive) and de-phosphorylation (active) of its E1 subunit, also known simply as pyruvate dehydrogenase (PDH) (Harris et al., 2002; Kim et al., 2006; Papandreou et al., 2006; Bonnet et al., 2007; McFate et al., 2008). PDH in humans has three phosphorylation sites that are regulated by pyruvate dehydrogenase kinases (PDK1-4) and pyruvate dehydrogenase phosphatases (PDP1,2), which are integral components of the PDC 
and are expressed in a tissue-dependent manner (Harris et al., 2002; Kolobova et al, 2001; Bowker-Kinley et al., 1998). When PDH is phosphorylated by PDK, PDC activity is downregulated and oxidative phosphorylation is depressed due to lack of pyruvate-derived substrate entering the citric acid cycle (Harris et al., 2002).

An added effect of the suppression of oxidative phosphorylation is the reduction in the mitochondrial production of reactive oxygen species (ROS) (Bonnet et al., 2007; Zhang et al., 2007). In excess, ROS can oxidize macromolecules and will eventually lead to dysfunctions and cell death via apoptosis (Zhang et al., 2007). The suppression of PDC activity may be one mechanism by which cancer cells increase life span and maintain high proliferation rates, since they require large amounts of ATP but do not seem to experience the negative effects of excessive ROS production (Bonnet et al, 2007; Zhang et al., 2007).

A main regulator of the hypoxia response in mammalian cells is hypoxia inducible factor-1 (HIF-1). HIF-1 is a heterodimeric transcriptional co-activator; it has an $\alpha$ - and $\beta$-subunit. The $\beta$-subunit (ARNT; aryl hydrocarbon receptor nuclear translocator) is constitutively expressed, so the regulation of HIF-1 activity is based on the steady-state concentration of HIF-1 $\alpha$ (Lluis et al., 2004; Kim et al., 2006; Papandreou et al., 2006). HIF-1 $\alpha$ is constantly expressed but is rapidly degraded under normoxic conditions. The mechanism behind HIFan intrinsic oxygen sensor, prolyl hydroxylase (PHD) that targets HIF- $1 \alpha$ for degradation in the presence of oxygen (Harris et al., 2002; Lluis et al., 2004; McFate et al., 2008). In the presence of oxygen, PHD hydroxylates proline residues on HIF- $1 \alpha$, which causes the binding of the von Hippel-Lindau tumor suppressor protein (pVHL), a component of an E3 ubiquitin ligase that recognizes the hydroxylated HIF- $1 \alpha$. HIF- $1 \alpha$ is then targeted for degradation by the proteosome (Lluis et al., 2004). However, without oxygen PHD cannot hydroxylate HIF- $1 \alpha$, so HIF- $1 \alpha$ is no t targeted by pVHL and accumulates, eventually binding with the $\beta$-subunit to form the HIF-1 dimer, which then translocates to the nucleus (Fig. 7) (Harris et al., 2002; Lluis et al., 2004). It is noteworthy that excess ROS also can apparently activate the HIF pathway by oxidizing the $\mathrm{Fe}^{2+}$ of prolyl hydroxylase thereby inhibiting its function (Brunelle et al., 2005).

HIF-1, along with co-activator p300/CBP, binds to DNA hypoxia response elements (HREs). A HRE is found in the promoter/enhancer region of the PDK-1 gene and facilitates its oxygen-dependent expression, and in turn, the downregulation of oxidative phosphorylation (Kim et al., 2006; Papandreou et al., 2006; McFate et al., 2008). HREs are also associated with promoter/enhancer regions of many glycolytic enzymes, which serves to upregulate their expression at low oxygen, increase glycolytic rate, and facilitate cell survival under hypoxia (Lluis et al., 2004; Kim et al., 2006; Papandreou et al., 2006; McFate et al., 2008). HIF-1 also activates the transcription of many glucose transporters so the cell can increase glucose flux to compensate for the low ATP yield of glycolytic metabolism (Semenza, 2007). This glycolytic poise allows the cell to maintain redox homeostasis and survive under hypoxic conditions (Semenza, 2010). HIF-1 operates this way in some forms of cancers. Certain types of cancer cells preferentially produce energy by glycolysis in the cytosol rather than by pyruvate oxidation in the mitochondria (Bellance et al., 2009; Jezek, 2010; Heiden et al., 2009).

\subsubsection{Preconditioning before cell stabilization: Insights from HIF-1 in hypoxia} and cancer-Metabolic restructuring during some natural states of dormancy (e.g., insect diapause, fish diapause, and the dauer state) displays similarities to the hypoxia response in mammalian cells. Both show a shift from an oxidative phosphorylation poise to a more glycolytic poise. Even with ample oxygen available, some types of cancers also utilize survival strategies that share similarities with the hypoxia response (e.g., Bellance et al., 2009; Jezek, 2010; Heiden et al., 2009). The downregulation of oxidative phosphorylation 
under normoxia and in the presence of high glucose is known as the Crabtree Effect (Crabtree, 1928). The upregulation of glycolysis under normoxic conditions is known as the Warburg Effect (Warburg et al., 1924; Warburg, 1956). The most extreme metabolic arrest during dormancy is seen in A. franciscana embryos and is associated with the longest survival duration; in this case energy flow is globally depressed in both diapause and anaerobic quiescence (see Sections 2 and 3.1, respectively). In order to mimic this severe arrest and promote an increased tolerance to extreme stresses in mammalian cells, it might prove advantageous to foster a Crabtree phenotype without also fostering a Warburg phenotype. That is, to downregulate the PDC independent of the HIF pathway, without actively shunting the cells toward a more glycolytic poise.

RNA interference (RNAi) is a mechanism that is used to control the activity of genes by knocking-down mRNA activity and protein expression. By using RNAi to knock down PDK1 in squamous cell carcinoma lines, McFate et al. (2008) show that PDC activity is restored and the cells shift away from the cancerous phenotype. Upregulation of PDC activity leads to a decrease in hypoxic cell survival and tumor growth (McFate et al., 2008). In contrast, RNAi that is used to target pyruvate dehydrogenase phosphatase could prevent the dephosphorylation and activation of the PDC. In this way the Crabtree phenotype could be fostered without the increased activation of multiple genes associated with the HIF pathway.

The synthetic glucocorticoid dexamethasone upregulates PDK4 mRNA in HepG2 cells and Morris hepatoma $7800 \mathrm{C} 1$ cells (Huang et al., 2002; Kwon et al., 2004). Dexamethasone also successfully protects primary hepatocytes from death receptor-mediated apoptosis (Oh et al., 2006) and stimulates the PI3K/Akt signaling cascade, which restricts mitochondrial respiration and inactivates multiple pathways of apoptosis initiation (Amaravadi and Thompson, 2005). Peroxisome proliferators-activated receptor- $\alpha$ (PPAR $\alpha$ ) agonists, such as WY-14,643 (Biomol Research Laboratories), increase PDK4 mRNA and protein levels (Huang et al, 2002). Finally, recent work by Gohil et al. (2010) shows that the over-thecounter drug meclizine suppresses oxidative phosphorylation in a way distinct from classic mechanisms like the HIF-1 response. More research is needed to understand this mechanism, but meclizine might prove to be another avenue by which to foster a Crabtree poise prior to processing cells for biostabilization.

\subsection{AMP Analogues for stimulation of the AMP-activated protein kinase}

The ability to increase the effective steady-state ratio of AMP to ATP in cells provides an opportunity to evaluate the impact of this change on rates of metabolism and cellular proliferation. As we have emphasized for some cases of diapause and anoxia-induced quiescence, one theme is that the AMP:ATP ratio is elevated and tightly correlated with the arrest of metabolism (Hochachka et al., 1993; Podrabsky and Hand, 1999, 2000; Reddy and Davies, 1993; Wegener, 1988). A high AMP:ATP ratio activates AMPK, which serves to conserve cellular energy stores (Hardie et al, 1998). Thus, we predicted that the AMPK cascade could be exploited for preconditioning mammalian cells, and indeed the induction of a stasis-like phenotype improves cell viability during cryopreservation of multiple mammalian cell lines and rat primary hepatocytes (Menze et al., 2010a).

The mechanism used for preconditioning by Menze et al. (2010a) is exposure of cells to 5aminoimidazole-4-carboxamide-1-b-D-ribofuranoside (AICAR). A property that contributes to the frequent use of AICAR is its ability to cross the cell membrane through the nucleoside transporter (Gadalla et al., 2004). After uptake into the cell, AICAR is phosphorylated by adenosine kinase to form 5-aminoimidazole-4-carboxamide-1b-D-ribofuranosyl-5'monophosphate (ZMP), which is membrane impermeable (Vincent et al., 1991). ZMP emulates several effects of AMP on AMPK, which include allosteric activation and 
activation of the upstream kinase LKB1 (Hardie, 2007; Henin et al., 1996; Merrill et al., 1997). However, it is appropriate to note that accumulation of ZMP, as well as other AICAR-derived metabolites (i.e., ZDP, ZTP), varies approximately 3.5-fold across the cell lines tested (Menze et al., 2010a).

AICAR has the potential to promote a number of the same metabolic features associated with diapause. Proliferation for a given cell line is negatively correlated with the foldincrease achieved in the 'effective adenylate ratio' ([AMP] + [ZMP])/[ATP] $)$ after AICAR treatment (Fig. 8a). An increased effective adenylate ratio serves to increase the activity of AMPK. This decreased cell proliferation promoted by AICAR is tightly associated with an increase in survivorship post-freezing for the various cell lines (Fig. 8b), expressed relative to control cells not pretreated with AICAR. Survivorship is also increased post-freezing for rat primary hepatocytes (Menze et al., 2010a). Thus for each cell line, the greater the depression of proliferation due to preconditioning with AICAR, the greater is the survivorship post-freezing. Interestingly, AICAR does not promote a change in metabolism of the J774 macrophages (Fig. 9), even though proliferation is markedly reduced by AICAR for this cell line. In contrast, AICAR treatment does promote metabolic depression in NIH/ 3T3 fibroblasts (Menze et al., 2010a). These cell-specific differences for the AICAR influences on metabolism again emphasize the importance of characterizing the effects of this compound on each cell type of interest.

Finally Fig. 9 displays the impact of another AMP analogue on the metabolism of J774 macrophages. Intracellular loading of adenosine-5'-O-thiomonophosphate (AMPS), a nonhydrolyzable analog of 5'-AMP and potent activator of AMPK, significantly depresses metabolism of macrophages; AMPS reduces proliferation of these cells as well (Menze et al., 2005). While AMPS is an even stronger activator of AMPK that is ZMP, the difficulty with the analogue is that is not membrane permeable. Thus cells must be transiently permeabilized to allow loading the APMS. In the case of the J774 macrophages, poration is accomplished by ATP-induced opening of the $\mathrm{P} 2 \mathrm{X}_{7}$ receptor channel; removal (dilution) of added ATP serves to close the channel (Menze et al., 2005). While the need for poration is a distinct disadvantage, the advantages are that AMPS is effective at lower concentrations than is ZMP; APMS loading has minimal impact on other components of the nucleotide pool; and AMPS avoids the issue of cell-type dependent variability in the conversion of AICAR to ZMP.

Thus metabolic preconditioning with AICAR is an effective means to increase cell survivorship during biostabilization. As pointed out in Section 5.1, a metabolic adjustment exhibited by some cancer cells (known for their high propensity for survival) is to direct pyruvate flux away from the TCA cycle and toward lactate production by inactivation of the pyruvate dehydrogenase complex. It seems that cell stability/survival can be enhanced and apoptosis depressed by turning down oxidative phosphorylation fueled by pyruvate. This metabolic restructuring is again similar to that seen in several forms of invertebrate diapause (pupal diapause of the flesh fly Sarcophaga crassipalpis, adult reproductive diapause of Drosophila melanogaster, and the larval dauer of C. elegans), where glycolytic metabolism is favored over oxidative phosphorylation (Ragland et al., 2010).

\section{Conclusions and future directions}

We have highlighted ways that animals exposed to energy-limited states for extended periods manage to survive. A recurring strategy to survive harsh environmental impact seems to involve a reduction in cell proliferation and the inhibition of metabolism, or at least a restructuring of metabolic pathways from oxidative phosphorylation to aerobic glycolysis. Lessons learned from organisms that naturally exhibit cell stasis and desiccation tolerance 
are improving our biostabilization procedures for mammalian cells. For example, pretreatment of mammalian cell lines with the AMPK activator AICAR promotes a reduction in cell proliferation (and in some cells metabolic depression) and is associated with improved survivorship after cryopreservation. Integrating such concepts of cell stasis into protocols for biostabilization may bring us closer to the exciting possibility of engineering mammalian cells and tissues that are more tolerant to long-term storage.

\section{Acknowledgments}

We thank the National Science Foundation (grant IOS-0920254 to S.C.H. and M.A.M.), the National Institutes of Health (grants 1-RO1-GM071345-01 and 2RO1DK046270-14A1 to M.T. and S.C.H.), Defense Advanced Research Projects Agency (grant N00173-01-1-G011 to M.T. and S.C.H.) and the William Wright Family Foundation (donation to S.C.H.) for generous support. J.A.R. received GIARs from Sigma Xi and the Orthoptera Society.

\section{References}

Alekseev, VR.; De Stasio, BT.; Gilbert, JJ. Diapause in Aquatic Invertebrates. Theory and Human Use. In: Dumont, HJ., editor. Monographiae Biologicae. 2007.

Alzamora R, Thali RF, Gong F, Smolak C, Li H, Baty CJ, Bertrand CA, Auchli Y, Brunisholz RA, Neumann D, Hallows KR, Pastor-Soler NM. PKA regulates vacuolar H+-ATPase localization and activity via direct phosphorylation of the A subunit in kidney cells. Journal of Biological Chemistry. 2010; 285:24676-24685. [PubMed: 20525692]

Amaravadi R, Thompson CB. The survival kinases Akt and Pim as potential pharmacological targets. Journal of Clinical Investigation. 2005; 115:2618-2624. [PubMed: 16200194]

Anchordoguy TJ, Hand SC. Acute blockage of the ubiquitin-mediated proteolytic pathway during invertebrate quiescence. American Journal of Physiology-Regulatory Integrative and Comparative Physiology. 1994; 267:R895-R900.

Anchordoguy TJ, Hand SC. Reactivation of ubiquitination in Artemia franciscana embryos during recovery from anoxia-induced quiescence. Journal of Experimental Biology. 1995; 198:1299-1305. [PubMed: 9319173]

Baker KD, Thummel CS. Diabetic larvae and obese flies - Emerging studies of metabolism in Drosophila. Cell Metabolism. 2007; 6:257-266. [PubMed: 17908555]

Bellance N, Patrick L, Rodrigue R. Mitochondria: from bioenergetics to the metabolic regulation of carcinogenesis. Frontiers in Bioscience. 2009; 14:4015-4034. [PubMed: 19273331]

Bonnet S, Archer SL, Allalunis-Turner J, Haromy A, Beaulieu C, Thompson R, Lee CT, Lopaschuk GD, Puttagunta L, Harry G, Hashimoto K, Porter CJ, Andrade MA, Thebaud B, Michelakis ED. A mitochondria-K+ channel axis is suppressed in cancer and its normalization promotes apoptosis and inhibits cancer growth. Cancer Cell. 2007; 11:37-51. [PubMed: 17222789]

Bowker-Kinley MM, Davis WI, Wu PF, Harris RA, Popov KM. Evidence for existence of tissuespecific regulation of the mammalian pyruvate dehydrogenase complex. Biochemical Journal. 1998; 329:191-196. [PubMed: 9405293]

Brunelle JK, Bell EL, Quesada NM, Vercauteren K, Tiranti V, Zeviani M, Scarpulla RC, Chandel NS. Oxygen sensing requires mitochondrial ROS but not oxidative phosphorylation. Cell Metabolism. 2005; 1:409-414. [PubMed: 16054090]

Buck LT, Hochachka PW. Anoxic suppression of Na+-K+-atpase and constant membrane-potential in hepatocytes - support for channel arrest. American Journal of Physiology. 1993; 265:R1020 R1025. [PubMed: 8238602]

Busa WB. How to succeed at anaerobiosis without really dying. Molecular Physiology. 1985; 8:351358.

Busa WB, Crowe JH, Matson GB. Intracellular $\mathrm{pH}$ and the metabolic status of dormant and developing Artemia embryos. Archives of Biochemistry and Biophysics. 1982; 216:711-718. [PubMed: 7114857]

Busa WB, Nuccitelli R. Metabolic regulation via intracellular pH. American Journal of Physiology. 1984; 246:R409-R438. [PubMed: 6326601] 
Cáceres CE. Dormancy in invertebrates. Invertebrate Biology. 1997; 116:371-383.

Cassada RC, Russell RL. The dauer-larva: A post-embryonic developmental variant of the nematode Caenorhabditis elegans. Developmental Biology. 1975; 46:326-342. [PubMed: 1183723]

Cheung U, Moghaddasi M, Hall HL, Smith JJB, Buck LT, Woodin MA. Excitatory actions of GABA mediate severe-hypoxia-induced depression of neuronal activity in the pond snail (Lymnaea stagnalis). Journal of Experimental Biology. 2006; 209:4429-4435. [PubMed: 17079713]

Clegg JS. Embryos of Artemia franciscana survive four years of continuous anoxia: The case for complete metabolic rate depression. Journal of Experimental Biology. 1997; 200:467-475. [PubMed: 9318130]

Clegg JS. Cryptobiosis - a peculiar state of biological organization. Comparative Biochemistry and Physiology B-Biochemistry \& Molecular Biology. 2001; 128:613-624.

Clegg JS. Desiccation tolerance in encysted embryos of the animal extremophile, Artemia. Integrative and Comparative Biology. 2005; 45:715-724.

Clegg JS. Protein stability in Artemia embryos during prolonged anoxia. Biological Bulletin. 2007; 212:74-81. [PubMed: 17301333]

Clegg JS, Drinkwater LE, Sorgeloos P. The metabolic status of diapause embryos of Artemia franciscana (SFB). Physiological Zoology. 1996; 69:49-66.

Covi JA, Hand SC. V-ATPase expression during development of Artemia franciscana embryos: potential role for proton gradients in anoxia signaling. Journal of Experimental Biology. 2005; 208:2783-2798. [PubMed: 16000547]

Covi JA, Hand SC. Energizing an invertebrate embryo: Bafilomycin-dependent respiration and the metabolic cost of proton pumping by the V-ATPase. Physiological and Biochemical Zoology. 2007; 80:422-432. [PubMed: 17508337]

Covi JA, Treleaven WD, Hand SC. V-ATPase inhibition prevents recovery from anoxia in Artemia franciscana embryos: quiescence signaling through dissipation of proton gradients. Journal of Experimental Biology. 2005; 208:2799-2808. [PubMed: 16000548]

Crabtree HG. The carbohydrate metabolism of certain pathological overgrowths. Biochemical Journal. 1928; 22:1289-1298. [PubMed: 16744142]

Crowe, JH.; Clegg, JS. Dry Biological Systems. Academic Press; New York, London: 1978.

Crowe, JH.; Crowe, LM.; Carpenter, JF.; Prestrelski, SJ.; Hoekstra, FA.; Araujo, P.; Panek, AD. Anhydrobiosis: cellular adaptation to extreme dehydration. In: Dantzler, WH., editor. Handbook of Physiology. Oxford University Press; Oxford, UK: 1997. p. 1445-1477.

Cunningham KA, Ashrafi K. Fat rationing in dauer times. Cell Metabolism. 2009; 9:113-114. [PubMed: 19187769]

Denlinger DL. Regulation of diapause. Annual Reviews of Entomology. 2002; 47:93-122.

Denlinger DL, Willis JH, Fraenkel G. Rates and cycles of oxygen-consumption during pupal diapause in Sarcophaga flesh flies. Journal of Insect Physiology. 1972; 18:871-882. [PubMed: 5024062]

Dutrieu J, Chrestia-Blanchine D. Resistance des oeufs durables hydrates d'Artemia salina a l'anoxie. Comptes Rendus Hebdomadaires Des Seances De L Academie Des Sciences Serie D. 1966; 263:998-1000.

Fielenbach N, Antebi A. C. elegans dauer formation and the molecular basis of plasticity. Genes \& Development. 2008; 22:2149-2165. [PubMed: 18708575]

Fuchs S, Bundy JG, Davies SK, Viney JM, Swire JS, Leroi AM. A metabolic signature of long life in Caenorhabditis elegans. BMC Biology. 2010; 8:14. [PubMed: 20146810]

Gadalla AE, Pearson T, Currie AJ, Dale N, Hawley SA, Sheehan M, Hirst W, Michel AD, Randall A, Hardie DG, Frenguelli BG. AICA riboside both activates AMP-activated protein kinase and competes with adenosine for the nucleoside transporter in the CA1 region of the rat hippocampus. Journal of Neurochemistry. 2004; 88:1272-1282. [PubMed: 15009683]

Gems D. Nematode ageing: Putting metabolic theories to the test. Current Biology. 1999; 9:R614R616. [PubMed: 10469585]

Glocker MO, Madi A, Mikkat S, Koy C, Ringel B, Thiesen HJ. Mass spectrometric proteome analysis suggests anaerobic shift in metabolism of dauer larvae of Caenorhabditis elegans. Biochimica Et Biophysica Acta-Proteins and Proteomics. 2008; 1784:1763-1770. 
Gohil VM, Sheth SA, Nilsson R, Wojtovich AP, Lee JH, Perocchi F, Chen W, Clish CB, Ayata C, Brookes PS, Mootha VK. Nutrient-sensitized screening for drugs that shift energy metabolism from mitochondrial respiration to glycolysis. Nature Biotechnology. 2010; 28:249-255.

Guppy M, Fuery CJ, Flanigan JE. Biochemical principles of metabolic depression. Comparative Biochemistry and Physiology B-Biochemistry \& Molecular Biology. 1994; 109:175-189.

Guppy M, Withers P. Metabolic depression in animals: physiological perspectives and biochemical generalizations. Biological Reviews. 1999; 74:1-40. [PubMed: 10396183]

Hahn DA, Denlinger DL. Meeting the energetic demands of insect diapause: Nutrient storage and utilization. Journal of Insect Physiology. 2007; 53:760-773. [PubMed: 17532002]

Hahn DA, Denlinger DL. Energetics of Insect Diapause. Annual Reviews of Entomology. 2011; 56:103-121.

Hand SC. Metabolic dormancy in aquatic invertebrates. Advances in Comparative and Environmental Physiology. 1991; 8:1-50.

Hand SC. Heat flow is measurable from Artemia franciscana embryos under anoxia. Journal of Experimental Zoology. 1995; 273:445-449.

Hand SC. Oxygen, pHi and arrest of biosynthesis. Acta Physiologica Scandinavica. 1997; 161:543551. [PubMed: 9429663]

Hand SC. Quiescence in Artemia franciscana embryos: Reversible arrest of metabolism and gene expression at low oxygen levels. Journal of Experimental Biology. 1998; 201:1233-1242. [PubMed: 9510534]

Hand, SC.; Hagedorn, M. New approaches for cell and animal preservation: lessons from aquatic organisms. In: Walsh, PJ.; S., LE.; Fleming, LE.; Solo-Gabriele, H.; Gerwick, WH., editors. Oceans and Human Health: Risks and Remedies from the Seas. 1 ed.. Academic Press; New York: 2008. p. 611-629.

Hand SC, Hardewig I. Downregulation of cellular metabolism during environmental stress: Mechanisms and implications. Annual Review of Physiology. 1996; 58:539-563.

Hand SC, Menze MA. Mitochondria in energy-limited states: mechanisms that blunt the signaling of cell death. Journal of Experimental Biology. 2008; 211:1829-1840. [PubMed: 18515712]

Hand SC, Podrabsky JE. Bioenergetics of diapause and quiescence in aquatic animals. Thermochimica Acta. 2000; 349:31-42.

Hand, SC.; Podrabsky, JE.; Eads, BD.; Van Breukelen, F. Interrupted development in aquatic organism: ecological context and physiological mechanism. In: Atkinson, D.; Thorndyke, M., editors. Environment and Animal Development. Genes, Life Histories and Plasticity. BIOS Scientific; Oxford: 2001. p. 219-234.

Hardie DG. AMP-activated/SNF1 protein kinases: conserved guardians of cellular energy. Nature Reviews Molecular Cell Biology. 2007; 8:774-785.

Hardie DG, Carling D, Carlson M. The AMP-activated/SNF1 protein kinase subfamily: Metabolic sensors of the eukaryotic cell? Annual Review of Biochemistry. 1998; 67:821-855.

Harris, RA.; Bowker-Kinley, MM.; Huang, BL.; Wu, PF. Regulation of the activity of the pyruvate dehydrogenase complex. In: Weber, G., editor. Advances in Enzyme Regulation, Vol 42, Proceedings. 2002. p. 249-259.

Heiden MGV, Cantley LC, Thompson CB. Understanding the Warburg effect: The metabolic requirements of cell proliferation. Science. 2009; 324:1029-1033. [PubMed: 19460998]

Henin N, Vincent MF, VandenBerghe G. Stimulation of rat liver AMP-activated protein kinase by AMP analogues. Biochimica Et Biophysica Acta-General Subjects. 1996; 1290:197-203.

Hochachka, PW.; Guppy, M. Metabolic Arrest and the Control of Biological Time. Harvard University Press; Cambridge, MA: 1987.

Hochachka PW, Nener JC, Hoar J, Saurez RK, Hand SC. Disconnecting metabolism from adenylate control during extreme oxygen limitation. Canadian Journal of Zoology-Revue Canadienne De Zoologie. 1993; 71:1267-1270.

Hoekstra FA, Wolkers WF, Buitink J, Golovina EA, Crowe JH, Crowe LM. Membrane stabilization in the dry state. Comparative Biochemistry and Physiology A. 1997; 117:335-341. 
Holt SJ, Riddle DL. SAGE surveys C. elegans carbohydrate metabolism: evidence for an anaerobic shift in the long-lived dauer larva. Mechanisms of Ageing and Development. 2003; 124:779-800. [PubMed: 12875742]

Houthoofd K, Braeckman BP, Lenaerts I, Brys K, De Vreese A, Van Eygen S, Vanfleteren JR. Ageing is reversed, and metabolism is reset to young levels in recovering dauer larvae of C. elegans. Experimental Gerontology. 2002; 37:1015-1021. [PubMed: 12213552]

Huang BL, Wu PF, Bowker-Kinley MM, Harris RA. Regulation of pyruvate dehydrogenase kinase expression by peroxisome proliferator-activated receptor-alpha ligands, glucocorticoids, and insulin. Diabetes. 2002; 51:276-283. [PubMed: 11812733]

Jezek P, Plecita-Hlavata L, Smolkova K, Rossignol R. Distinctions and similarities of cell bioenergetics and the role of mitochondria in hypoxia, cancer, and embryonic development. International Journal of Biochemistry \& Cell Biology. 2010; 42:604-622. [PubMed: 19931409]

Kane PM, Smardon AM. Assembly and regulation of the yeast vacuolar H+-ATPase. Journal of Bioenergetics and Biomembranes. 2003; 35:313-321. [PubMed: 14635777]

Kenyon CJ. The genetics of ageing. Nature. 2010; 464:504-512. [PubMed: 20336132]

Kim JW, Tchernyshyov I, Semenza GL, Dang CV. HIF-1-mediated expression of pyruvate dehydrogenase kinase: A metabolic switch required for cellular adaptation to hypoxia. Cell Metabolism. 2006; 3:177-185. [PubMed: 16517405]

Kolobova E, Tuganova A, Boulatnikov I, Popov KM. Regulation of pyruvate dehydrogenase activity through phosphorylation at multiple sites. Biochemical Journal. 2001; 358:69-77. [PubMed: 11485553]

Kostál V. Eco-physiological phases of insect diapause. Journal of Insect Physiology. 2006; 52:113127. [PubMed: 16332347]

Kwast KE, Shapiro JI, Rees BB, Hand SC. Oxidative-phosphorylation and the realkalinization of intracellular $\mathrm{pH}$ during recovery from anoxia in Artemia franciscana embryos. Biochimica $\mathrm{Et}$ Biophysica Acta-Bioenergetics. 1995; 1232:5-12.

Kwon HS, Huang B, Unterman TG, Harris RA. Protein kinase B-alpha inhibits human pyruvate dehydrogenase kinase- 4 gene induction by dexamethasone through inactivation of FOXO transcription factors. Diabetes. 2004; 53:899-910. [PubMed: 15047604]

Lafourcade C, Sobo K, Kieffer-Jaquinod S, Garin J, van der Goot FG. Regulation of the V-ATPase along the endocytic pathway occurs through reversible subunit association and membrane localization. PLoS ONE. 2008; 3:e2758. [PubMed: 18648502]

Lees, AD. Physiology of Diapause in Arthropods. Cambridge University Press; Cambridge: 1955.

Lluis JM, Morales A, Blasco C, Colell A, Mari M, Garcia-Ruiz C, Fernandez-Checa JC. Critical role of mitochondrial glutathione in the survival of hepatocytes during hypoxia. Journal of Biological Chemistry. 2005; 280:3224-3232. [PubMed: 15548523]

Lutz PL. Mechanisms for anoxic survival in the vertebrate brain. Annual Review of Physiology. 1992; 54:601-618.

Lutz PL, Milton SL. Negotiating brain anoxia survival in the turtle. Journal of Experimental Biology. 2004; 207:3141-3147. [PubMed: 15299035]

Mabon ME, Scott BA, Crowder CM. Divergent mechanisms controlling hypoxic sensitivity and lifespan by the DAF-2/Insulin/IGF-receptor pathway. PLoS ONE. 2009; 4:e7937. [PubMed: 19936206]

McFate T, Mohyeldin A, Lu H, Thakar J, Henriques J, Halim ND, Wu H, Schell MJ, Tsang TM, Teahan O, Zhou S, Califano JA, Jeoung NH, Harris RA, Verma A. Pyruvate dehydrogenase complex activity controls metabolic and malignant phenotype in cancer cells. Journal of Biological Chemistry. 2008; 283:22700-22708. [PubMed: 18541534]

Menze MA, Boswell L, Toner M, Hand SC. Occurrence of mitochondria-targeted LEA gene in animals increases organelle resistance to water stress. Journal of Biological Chemistry. 2009; 284(16):10714-10719. [PubMed: 19228698]

Menze MA, Chakraborty N, Clavenna M, Banerjee M, Liu XH, Toner M, Hand SC. Metabolic preconditioning of cells with AICAR-riboside: Improved cryopreservation and cell-type specific impacts on energetics and proliferation. Cryobiology. 2010a; 61:79-88. [PubMed: 20510224] 
Menze MA, Clavenna MJ, Hand SC. Depression of cell metabolism and proliferation by membranepermeable and -impermeable modulators: role for AMP-to-ATP ratio. American Journal of Physiology-Regulatory Integrative and Comparative Physiology. 2005; 288:R501-R510.

Menze MA, Fortner G, Nag S, Hand SC. Mechanisms of apoptosis in Crustacea: what conditions induce versus suppress cell death? Apoptosis. 2010b; 15:293-312. [PubMed: 20043212]

Merrill GF, Kurth EJ, Hardie DG, Winder WW. AICA riboside increases AMP-activated protein kinase, fatty acid oxidation, and glucose uptake in rat muscle. American Journal of PhysiologyEndocrinology and Metabolism. 1997; 36:E1107-E1112.

Myers GS. Annual Fishes. Aquarium Journal. 1952; 23:125-141.

Narbonne P, Roy R. Inhibition of germline proliferation during C. elegans dauer development requires PTEN, LKB1 and AMPK signalling. Development. 2006; 133:611-619. [PubMed: 16407400]

Narbonne P, Roy R. Caenorhabditis elegans dauers need LKB1/AMPK to ration lipid reserves and ensure long-term survival. Nature. 2009; 457:210-214. [PubMed: 19052547]

Nico LG, Thomerson JE. Ecology, food habits and spatial interactions of Orinoco Basin annual killifish. Acta Biologica Venezuela. 1989; 12:106-120.

Oh HY, Namkoong S, Lee SJ, Por E, Kim CK, Billiar TR, Han JA, Ha KS, Chung HT, Kwon YG, Lee H, Kim YM. Dexamethasone protects primary cultured hepatocytes from death receptor-mediated apoptosis by upregulation of cFLIP. Cell Death and Differentiation. 2006; 13:512-523. [PubMed: 16167066]

O'Riordan VB, Burnell AM. Intermediary metabolism in the dauer larva of the nematode Caenorhabditis elegans - I. Glycolysis, gluconeogenesis, oxidative phosphorylation and the tricarboxylic acid cycle. Comparative Biochemistry and Physiology Part B: Comparative Biochemistry. 1989; 92:233-238.

O'Riordan VB, Burnell AM. Intermediary metabolism in the dauer larva of the nematode Caenorhabditis elegans--II. The glyoxylate cycle and fatty-acid oxidation. Comparative Biochemistry and Physiology Part B: Comparative Biochemistry. 1990; 95:125-130.

Papandreou I, Cairns RA, Fontana L, Lim AL, Denko NC. HIF-1 mediates adaptation to hypoxia by actively downregulating mitochondrial oxygen consumption. Cell Metabolism. 2006; 3:187-197. [PubMed: 16517406]

Peters N. Embryonale anpassungen oviparer zahnkarpfen aus periodisch austrocknenden gewassern. International Reviews in Gestational Hydrobiology. 1963; 48:257-313.

Podrabsky JE, Hand SC. The bioenergetics of embryonic diapause in an annual killifish, Austrofundulus limnaeus. Journal of Experimental Biology. 1999; 202:2567-2580. [PubMed: 10482717]

Podrabsky JE, Hand SC. Depression of protein synthesis during diapause in embryos of the annual killifish Austrofundulus limnaeus. Physiological and Biochemical Zoology. 2000; 73:799-808. [PubMed: 11121353]

Podrabsky JE, Lopez JP, Fan TWM, Higashi R, Somero GN. Extreme anoxia tolerance in embryos of the annual killifish Austrofundulus limnaeus: Insights from a metabolomics analysis. Journal of Experimental Biology. 2007; 210:2253-2266. [PubMed: 17575031]

Ragland GJ, Denlinger DL, Hahn DA. Mechanisms of suspended animation are revealed by transcript profiling of diapause in the flesh fly. Proceedings of the National Academy of Sciences of the United States of America. 2010; 107:14909-14914. [PubMed: 20668242]

Rakshpal R. Respiratory metabolism during embryogenesis of a diapause species of field cricket, Gryllus pennsylvanicus Burmeister (orthoptera, gryllidae). Journal of Insect Physiology. 1962; $8: 217-221$.

Reddy DC, Davies RW. Metabolic adaptations by the leech Nephelopsis obscura during long-term anoxia and recovery. Journal of Experimental Zoology. 1993; 265:224-230.

Rein J, Voss M, Blenau W, Walz B, Baumann O. Hormone-induced assembly and activation of VATPase in blowfly salivary glands is mediated by protein kinase A. American Journal of Physiology-Cell Physiology. 2008; 294:C56-C65. [PubMed: 17977948]

Reynolds JA, Hand SC. Differences in isolated mitochondria are insufficient to account for respiratory depression during diapause in Artemia franciscana embryos. Physiological and Biochemical Zoology. 2004; 77:366-377. [PubMed: 15286911] 
Reynolds JA, Hand SC. Decoupling development and energy flow during embryonic diapause in the cricket, Allonemobius socius. Journal of Experimental Biology. 2009a; 212:2064-2073.

Reynolds JA, Hand SC. Embryonic diapause highlighted by differential expression of mRNAs for ecdysteroidogenesis, transcription and lipid sparing in the cricket Allonemobius socius. Journal of Experimental Biology. 2009b; 212:2074-2083.

Riddle, DL.; Albert, PS. Genetic and environmental regulation of dauer larva development. In: Riddle, D.L.e.a., editor. C elegans II. Cold Spring Harbor Laboratory Press; Cold Spring Harbor, NY: 1997. p. 739-768.

Rinehart JP, Robich RM, Denlinger DL. Isolation of diapause-regulated genes from the flesh fly, Sarcophaga crassipalpis by suppressive subtractive hybridization. Journal of Insect Physiology. 2010; 56:603-609. [PubMed: 20026067]

Roemhild G. Respiration of eggs and parts of eggs of Aulocara elliotti (Thomas). Physiological Zoology. 1965; 38:213-218.

Ruderman NB, Xu XJ, Nelson L, Cacicedo JM, Saha AK, Lan F, Ido Y. AMPK and SIRT1: a longstanding partnership? American Journal of Physiology-Endocrinology and Metabolism. 2010; 298:E751-E760. [PubMed: 20103737]

Semenza GL. HIF-1 mediates the Warburg effect in clear cell renal carcinoma. Journal of Bioenergetics and Biomembranes. 2007; 39:231-234. [PubMed: 17551816]

Semenza GL. HIF-1: upstream and downstream of cancer metabolism. Current Opinion in Genetics \& Development. 2010; 20:51-56. [PubMed: 19942427]

Sim C, Denlinger DL. Insulin signaling and FOXO regulate the overwintering diapause of the mosquito Culex pipiens. Proceedings of the National Academy of Sciences of the United States of America. 2008; 105:6777-6781. [PubMed: 18448677]

Slama K, Denlinger DL. Infradian cycles of oxygen-consumption in diapausing pupae of the flesh fly, Sarcophaga crassipalpis, monitored by a scanning microrespirographic method. Archives of Insect Biochemistry and Physiology. 1992; 20:135-143. [PubMed: 1504318]

Steinberg GR, Kemp BE. AMPK in health and disease. Physiological Reviews. 2009; 89:1025-1078. [PubMed: 19584320]

Stocco DM, Warner AH, Beers PC. Effect of anoxia on nucleotide metabolism in encysted embryos of brine shrimp. Developmental Biology. 1972; 27:479-493. [PubMed: 5029495]

Storey KB. Anoxia tolerance in turtles: Metabolic regulation and gene expression. Comparative Biochemistry and Physiology A-Molecular \& Integrative Physiology. 2007; 147:263-276.

Storey KB, Storey JM. Tribute to P. L. Lutz: putting life on 'pause' - molecular regulation of hypometabolism. Journal of Experimental Biology. 2007; 210:1700-1714. [PubMed: 17488933]

Tauber MJ, Tauber CA. Insect seasonality - diapause maintenance, termination, and post-diapause development. Annual Reviews of Entomology. 1976; 21:81-107.

Urbanski JM, Benoit JB, Michaud MR, Denlinger DL, Armbruster P. The molecular physiology of increased egg desiccation resistance during diapause in the invasive mosquito, Aedes albopictus. Proceedings of the Royal Society B-Biological Sciences. 2010; 277:2683-2692.

van Breukelen F, Hand SC. Characterization of ATP-dependent proteolysis in embryos of the brine shrimp, Artemia franciscana. Journal of Comparative Physiology B-Biochemical Systemic and Environmental Physiology. 2000; 170:125-133.

van Breukelen F, Maier R, Hand SC. Depression of nuclear transcription and extension of mRNA halflife under anoxia in Artemia franciscana embryos. Journal of Experimental Biology. 2000; 203:1123-1130. [PubMed: 10708633]

Vanfleteren JR, De Vreese A. The gerontogenes age-1 and daf-2 determine metabolic rate potential in aging Caenorhabditis elegans. FASEB Journal. 1995; 9:1355-1361. [PubMed: 7557026]

Vanfleteren JR, De Vreese A. Rate of aerobic metabolism and superoxide production rate potential in the nematode Caenorhabditis elegans. Journal of Experimental Zoology. 1996; 274:93-100. [PubMed: 8742689]

Vincent MF, Marangos PJ, Gruber HE, Vandenberghe G. Inhibition by AICA riboside of gluconeogenesis in isolated rat hepatocytes. Diabetes. 1991; 40:1259-1266. [PubMed: 1657665]

Wang J, Kim SK. Global analysis of dauer gene expression in Caenorhabditis elegans. Development. 2003; 130:1621-1634. [PubMed: 12620986] 
Warburg O. Origin of cancer cells. Science. 1956; 123:309-314. [PubMed: 13298683]

Warburg O, Posener K, Negelein E. Über den stoffwechsel der tumoren. Biochemische Zeitschrift. $1924 ; 152: 319-344$.

Warner AH, Clegg JS. Diguanosine nucleotide metabolism and the survival of Artemia embryos during years of continuous anoxia. European Journal of Biochemistry. 2001; 268:1568-1576. [PubMed: 11248674]

Warner AH, Jackson SA, Clegg JS. Effect of anaerobiosis on cysteine protease regulation during the embryonic-larval transition in Artemia franciscana. Journal of Experimental Biology. 1997; 200:897-908. [PubMed: 9318685]

Wegener, G. Oxygen availability energy metabolism and metabolic rate in invertebrates and vertebrates. In: Acker, H., editor. Oxygen Sensing Tissues. Springer-Verlag; Berlin: 1988. p. 13-35.Berlin

Wieczorek H, Huss M, Merzendorfer H, Reineke S, Vitavska O, Zeiske W. The insect plasma membrane $\mathrm{H}+\mathrm{V}$-ATPase: Intra-, inter-, and supramolecular aspects. Journal of Bioenergetics and Biomembranes. 2003; 35:359-366. [PubMed: 14635781]

Zhang HF, Gao P, Fukuda R, Kumar G, Krishnamachary B, Zeller KI, Dang CV, Semenza GL. HIF-1 inhibits mitochondrial biogenesis and cellular respiration in VHL-deficient renal cell carcinoma by repression of C-MYC activity. Cancer Cell. 2007; 11:407-420. [PubMed: 17482131]

Zhang YQ, Gamarra S, Garcia-Effron G, Park S, Perlin DS, Rao R. Requirement for ergosterol in VATPase function underlies antifungal activity of azole drugs. PLoS Pathogens. 2010; 6:e1000939. [PubMed: 20532216] 


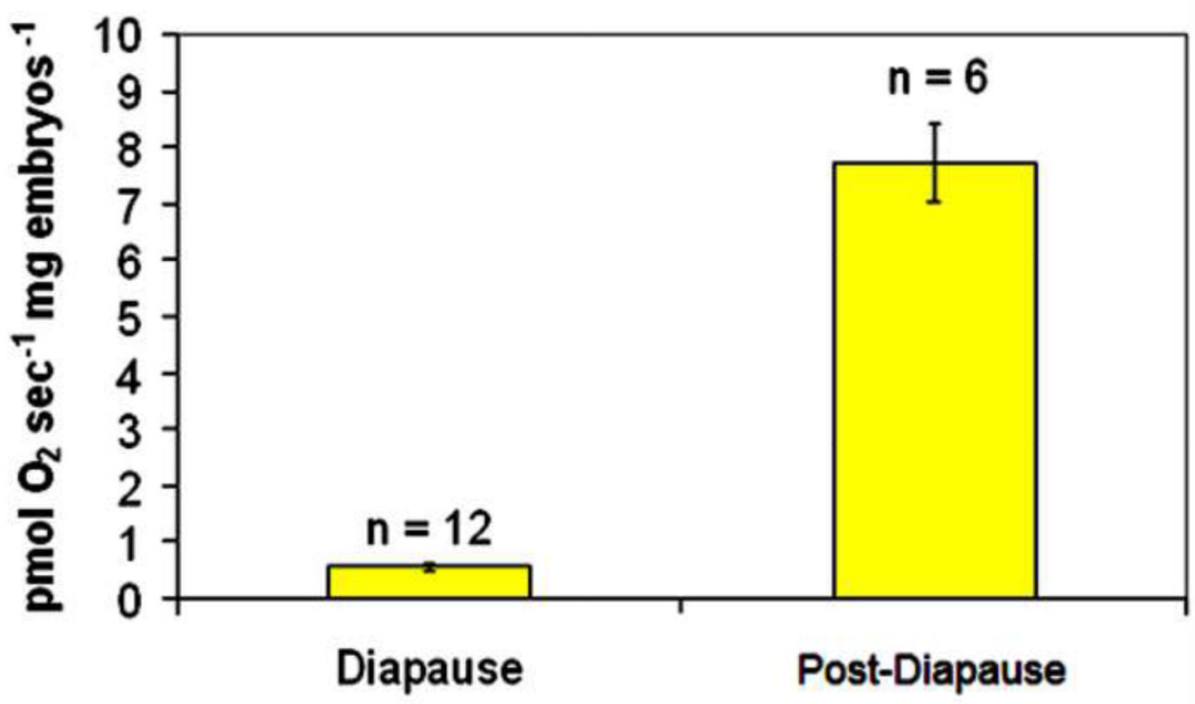

Figure 1.

Oxygen consumption by encysted embryos of Artemia franciscana. Respiration rates of embryos in diapause are significantly depressed compared to postdiapause embryos that have developed at room temperature for $8 \mathrm{~h}$. Bars represent mean \pm SEM. (adapted from Reynolds and Hand, 2004). 


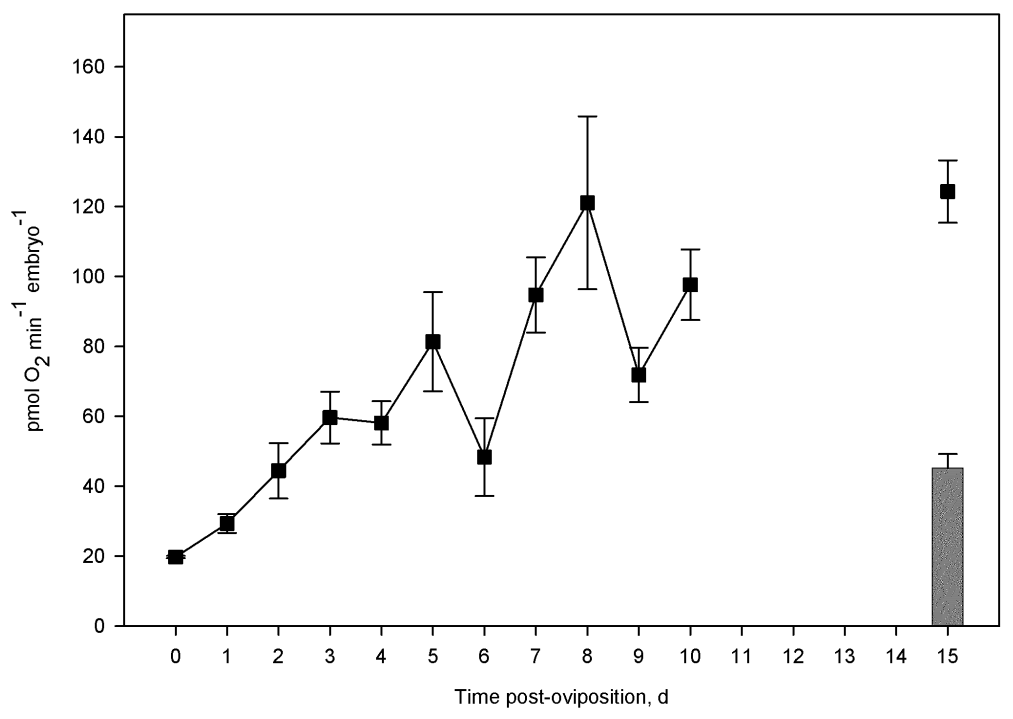

Figure 2.

Respiration rate of $A$. socius embryos as a function of time after post-oviposition. (values are means \pm s.e.m., $n=3-12$ samples of 100 embryos for each time point). The bar indicates respiration rate of diapause embryos 15 days post-oviposition (mean $\pm \mathrm{SEM}, n=22$ ). (adapted from Reynolds and Hand 2009a). 


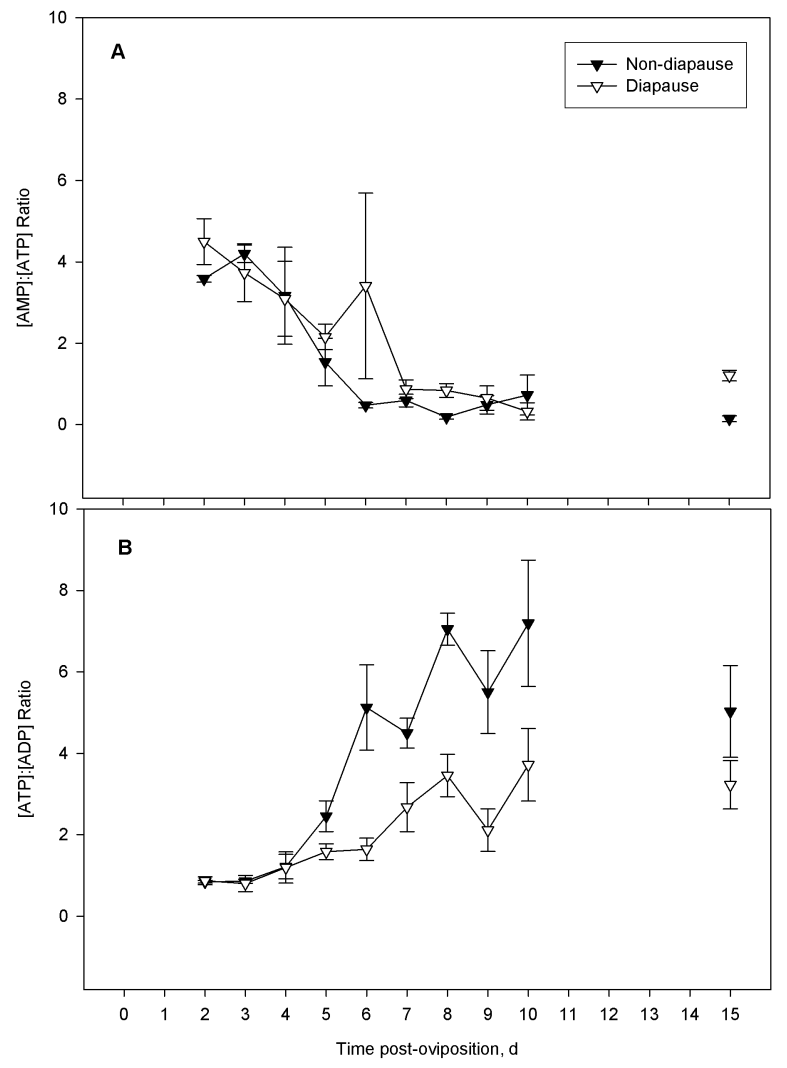

Figure 3.

Adenine nucleotide ratios in A. socius embryos. (A) [AMP]:[ATP] ratios and (B) [ATP]: $[\mathrm{ADP}]$ ratios of non-diapause and diapause embryos as a function of developmental time. Values are means \pm SEM, $n=3-6$ samples of 200-300 embryos for each time point. (adapted from Reynolds and Hand 2009a). 


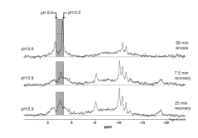

Figure 4.

Intracellular $\mathrm{pH}$ and NTP/NDP status of dechorionated A. franciscana embryos for longterm pre-treatment with bafilomycin as observed with ${ }^{31} \mathrm{P}-\mathrm{NMR}$. Spectra are displayed for $58 \mathrm{~min}$ of anoxia followed by $7.5 \mathrm{~min}$ and $25 \mathrm{~min}$ of aerobic recovery. Shaded boxes serve to emphasize changes in chemical shift and shape of the Pi peaks. (adapted from Covi et al., 2005). 

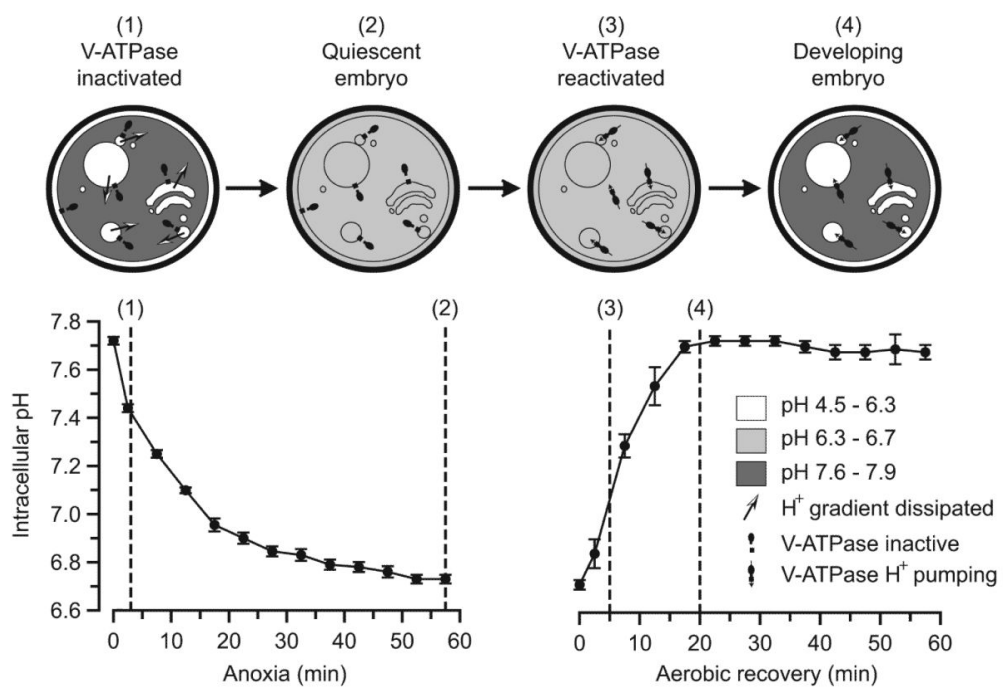

Figure 5.

Exposure to anoxia induces a drop in cellular ATP as oxidative phosphorylation is arrested. Within the first 5 min of exposure to anoxia, a cessation of proton transport by the VATPase and an activation of proton dissipative paths occur. The combined result is a 1 unit drop in intracellular $\mathrm{pH}$ over approximately $1 \mathrm{~h}$. The return of oxidative phosphorylation upon reoxygenation of the embryos causes ATP levels to rise, which in turn activates the VATPase. Subsequent proton pumping into the intracellular compartment causes further alkalinization of $\mathrm{pHi}$, which in turn helps to facilitate the resumption of development and metabolic processes inhibited by low pH. (adapted from Covi et al., 2005) 


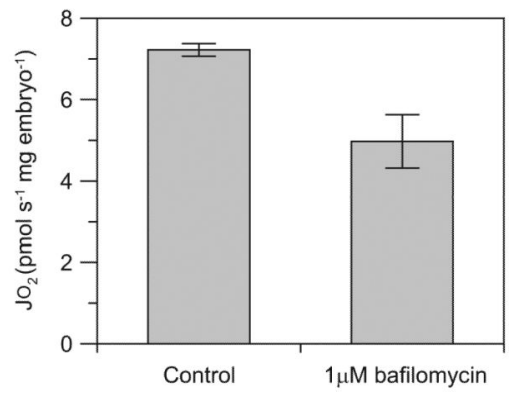

Figure 6.

Effect of preincubation with $1 \mathrm{mmol}^{-1}$ bafilomycin on oxygen consumption of Artemia franciscana embryos. An asterisk indicates a significant difference from untreated controls (mean $\pm \mathrm{SEM} ; n=3$ ). (adapted from Covi and Hand, 2007). 


\section{Oxygen Sensing by the HIF-1 Induction System and HIF-1 Regulation of Gene Expression}

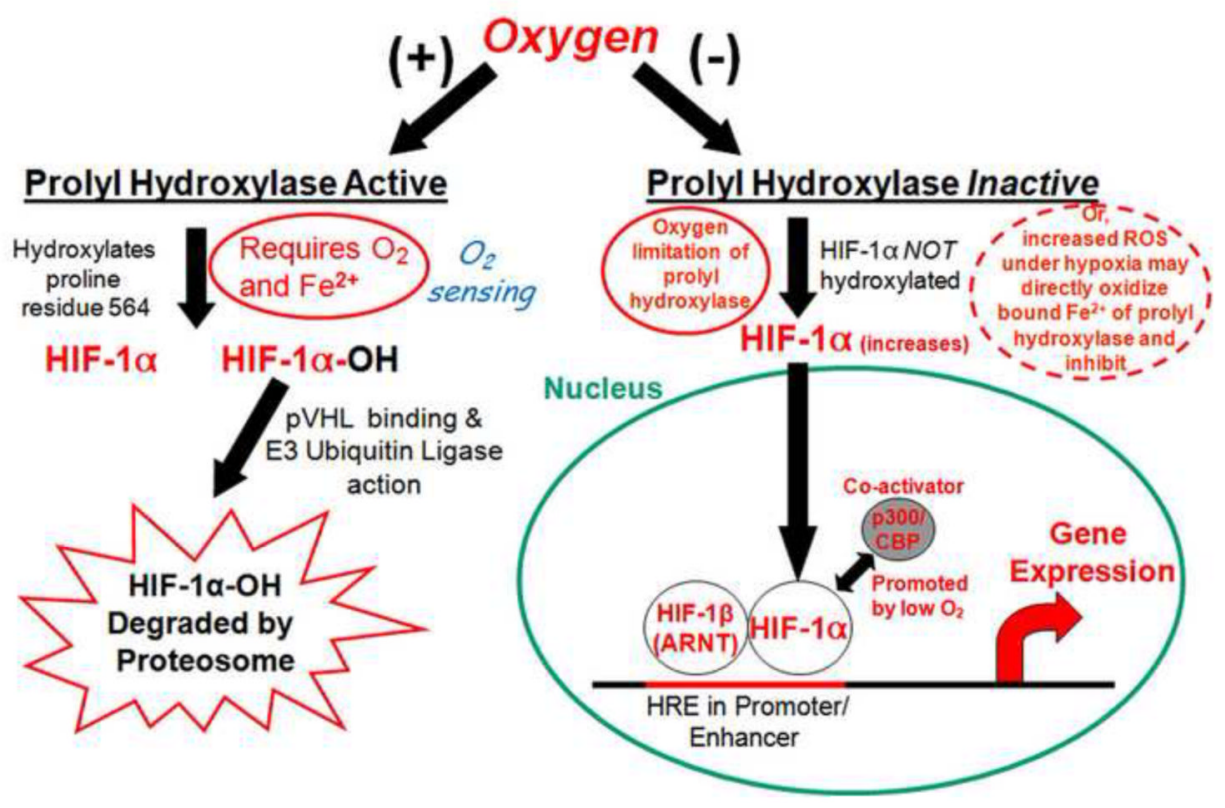

Figure 7.

Model for the regulation of HIF-1. Oxygen and $\mathrm{Fe}^{2+}$ are required for normal functioning of prolyl hydroxylase (PH), which tags HIF- $1 \alpha$ for degradation. Hypoxia disrupts PH activity, elevates HIF- $1 \alpha$ and fosters PDK1 expression. Under normoxia, $\mathrm{CoCl}_{2}$ or desferrioxamine can displace/chelate the required $\mathrm{Fe}^{2+}$ thereby inactivating PH, elevating HIF-1 $\alpha$, and triggering gene expression. 


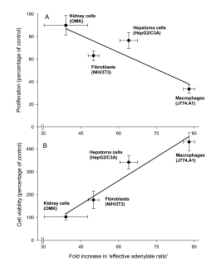

Figure 8.

(A) Depression in cell proliferation is correlated with the fold-increase in the 'effective adenylate ratio' after AICAR treatment ([AMP] + [ZMP])/[ATP $]$ ), expressed relative to control values. (B) Fold-increase in cell viability after freezing (number of viable cells after freezing with AICAR/number of viable cells after freezing without AICAR). The effect of AICAR on viability after freezing positively correlates with the fold-increase in the 'effective adenylate ratio'. (redrawn from Menze et al., 2010a). 


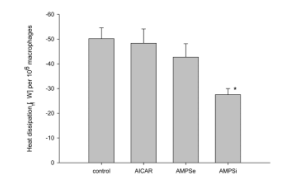

Figure 9.

Heat dissipation of mouse macrophage cells (J774.A1) after treatment with stimulators of AMP-activated protein kinase. Control values are for untreated cells. AICAR exposure was for $24 \mathrm{~h}$ at a concentration of $2 \mathrm{mM}$. AMPS treatment requires that cells are first porated to allow loading with this membrane-impermeable analog of AMP. Poration is accomplished by exposure of cells to $5 \mathrm{mM}$ ATP to transiently open the $\mathrm{P} 2 \mathrm{X}_{7}$ receptor channel (for details see Menze et al., 2005). The AMPSi values represent cells porated in the presence of $10 \mathrm{mM}$ AMPS and should be compared to the AMPSe values (poration control) in which cells were porated in the absence of AMPS. *Significant difference in heat production after poration with $10 \mathrm{mM}$ AMPS (AMPSi) compared with the poration control (AMPSe), $P \leq 0.05$. Each bar represents mean $\pm \mathrm{SD}$ of $n=3-7$ separate measurements. (redrawn from Menze et al., 2005). 